\title{
THE FIRST NUMERO OF THOMAS SAY'S AMERICAN ENTO- MOLOGY AND TWO LETTERS ON THE HESSIAN FLY HITHERTO NOT MENTIONED AMONG HIS PUBLISHED PAPERS.
}

BY DR. HERMANN AUgUST HAGEN, CAMBRIDGE, MASS.

I bought, in I 850 , out of the library of the late W. Von Winthem, in Hamburg, the first numero of Say's American entomology, r8r7; the first volume of his American entomology, I824; and the glossary, i825. All three are in the original binding and the two latter with the inscription on the title: "To Mr. Wm. W. von Winthem from his friend the author." All belong now to the library of the Museum of comparative zoology.

The first numero of volume 1 of the Amer. entomology, $\mathrm{I}_{1} \mathbf{7}$, is extremely rare; indeed $I$ have never seen another copy than mine in Europe or in America, and was also assured by the best authority, Mr. S. H. Scudder, that he had never seen a copy. Dr. J. L. LeConte, in his edition of Say's works, I 859 , v. 2, p. I, note, says : "These references are to the suppressed first edition of the American entomology, which I have never seen." Later, in 1872 , when I showed my copy to the late Doctor, he answered that he possessed a similar copy. Perhaps my memory is wrong; at least in the printed catalogue of his library it is not mentioned.

I suppose some details about this rare book may not be out of place. Say, in the preface of vol. I, i 824, p. vii, says: "Six plates of the present volume, together with their accompa- nying text, were printed off in the year I 8 I 7 , but as they were never properly published, it has been thought advisable to include them in the present wo1k."

The little volume is printed on the same paper and same size as vol. I, I 824 ; the cover has the same nice vignette (two Cupids catching insects), but marked vol. I, no. I, and Kneass, Young and Co. etc., which is also repeated on the title plate. The title is American | Entomology | or | Descriptions | of the | Insects of North America | illustrated by / Coloured Figures | from | Drawings executed from nature | by Thomas Say | Member of the Academy of Natural Sciences of Philadelphia etc. I (the verses from Stillingfleet as in 1824) Philadelphia | published by Mitchell and Ames |W. Brown, Printer, Prune Street. | I8I 7.-

Then follows, $p$. iii to $x$, a preface entirely different from that in 1824 .

The six plates have no numero nor the name of the engraver, exactly as in volume I, I824, where the same six plates are alone not numbered.

I. Papilio Philenor, with three pages of text, marked Plate I (the same numero in 1824 ).

2. Geotrupes Tityus, with 4 pages of text, marked Pl. II (Scarabaeus Tityus, pl. 4, in I824). 
3. Nemognatha immaculata, with 2 pages of text, marked Pl. III (pl. 7 in 1824 ).

4. Notoxus monodon, the lower fig., and $N$. bicolor, with 4 pages of text, marked Pl. IV (Anthicus bicolor and $A$. monodon, pl. 1o, in 1824 ).

5. Berytus spinosus, with 3 pages of text, marked Pl. V (pl. 14, in I 824).

6. Cicindela formosa, and C. decemnotata, with 4 pages of text, marked Pl. VI, and followed by an index of the 8 species figured ( $\mathrm{pl}$. 18 in $\mathrm{r} 824$ ).

The text in 1824 is throughout different from the text in 1817 , mostly shortened, but scarcely different for the descriptive part of the species. The coloration of the plates is more careful than in 1824 and better than in LeConte's edition.

The Memoirs of the Philadelphia society for promoting agriculture, vol. 4, Philadelphia, I8r $8,8^{\circ}$, contain two letters of Thomas Say, which are not mentioned in Douhleday's List of Thomas Say's works, nor in LeConte's edition, nor quoted by Th. W. Harris. Dr. Asa Fitch states that he has never seen this rare book. The volumes were presented to the Library of Harvard college in 1849 , after Harris had done his work. He knew it, but as it contains nothing of importance it is not quoted by Harris, though in one volume a letter to him is found on the cover.

r. A letter, Sept. 28, ISI7, to Hon. R. Peters, by Thomas Say, p. 224-226, containing remarks on the Hessian fly, on the locust and on corn grubs.

2. A letter, p. 236-237, to the same, by Thomas Say, containing remarks on the Hessian fly, on Tinea granella, and on cut worms.

[The references to these two articles, which were written out several years since, are added in the Bibliographical record, nos. $343^{\circ}$ and 343 I. $-B . P . M$.]

Sound-producing organs in Anomala, Anthonomus, AND other COLEOPTERA.- There is a stridulating organ in Anomala, situated on the metathorax and elytra, in the same position as described by me in Polyphylla (Psyche, v. 2, p. 278). Its location is the same as that of the elytral organ described by Dr. LeConte (Class. col. N. A.) in Trox and Ligyrus, but Dr. LeConte failed to notice that the metathorax in those genera has on its ascending portion (beneath a ridge in Trox) a corresponding pearly space, just as it has in Polyphylla; this is in addition to the organ on the first ventral, corresponding: to the third dorsal, segment, in Trox, described by Dr. LeConte. My finding these organs in melolonthini and rutel$i n i$ is merely accidental: why does not some coleopterist study them microscopically in all our genera of scarabacidae? The same organs are present in Limonius and other elateridae, and there is, besides, a surface on the ascending portion of the first ventral segment, as in Trox, which, as in Trox, corresponds to a second surface on the elytra. I find stridulating organs also in $A n_{-}$ thonomus, of the curculionidae, situated as in Anomala.

Waterbury, Conn., I3 Now. 1883 .

W. H. Patton.

「Stridulating organs of coleoptera are described in Piycile, Rec., no. I405, I444.। 

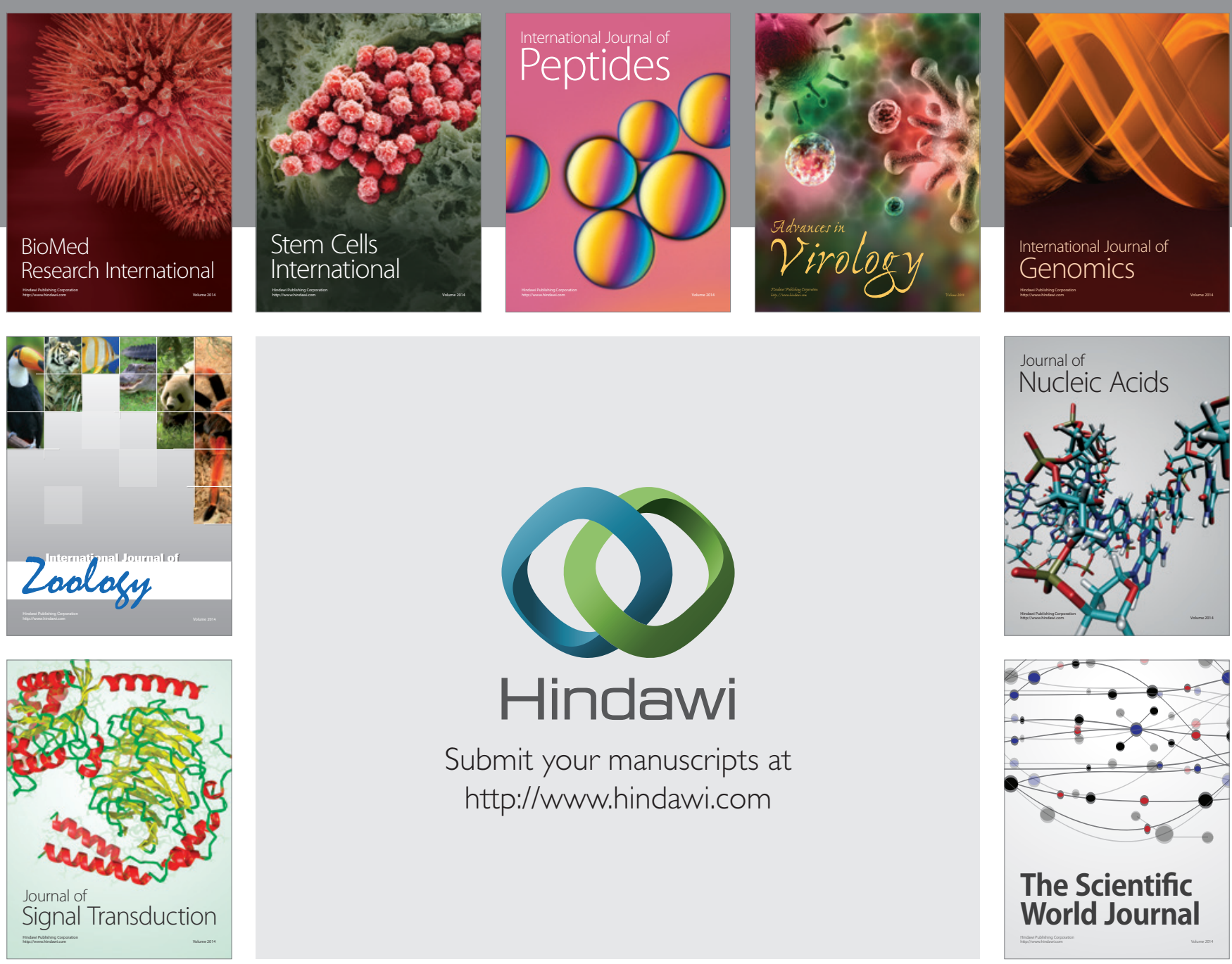

Submit your manuscripts at

http://www.hindawi.com
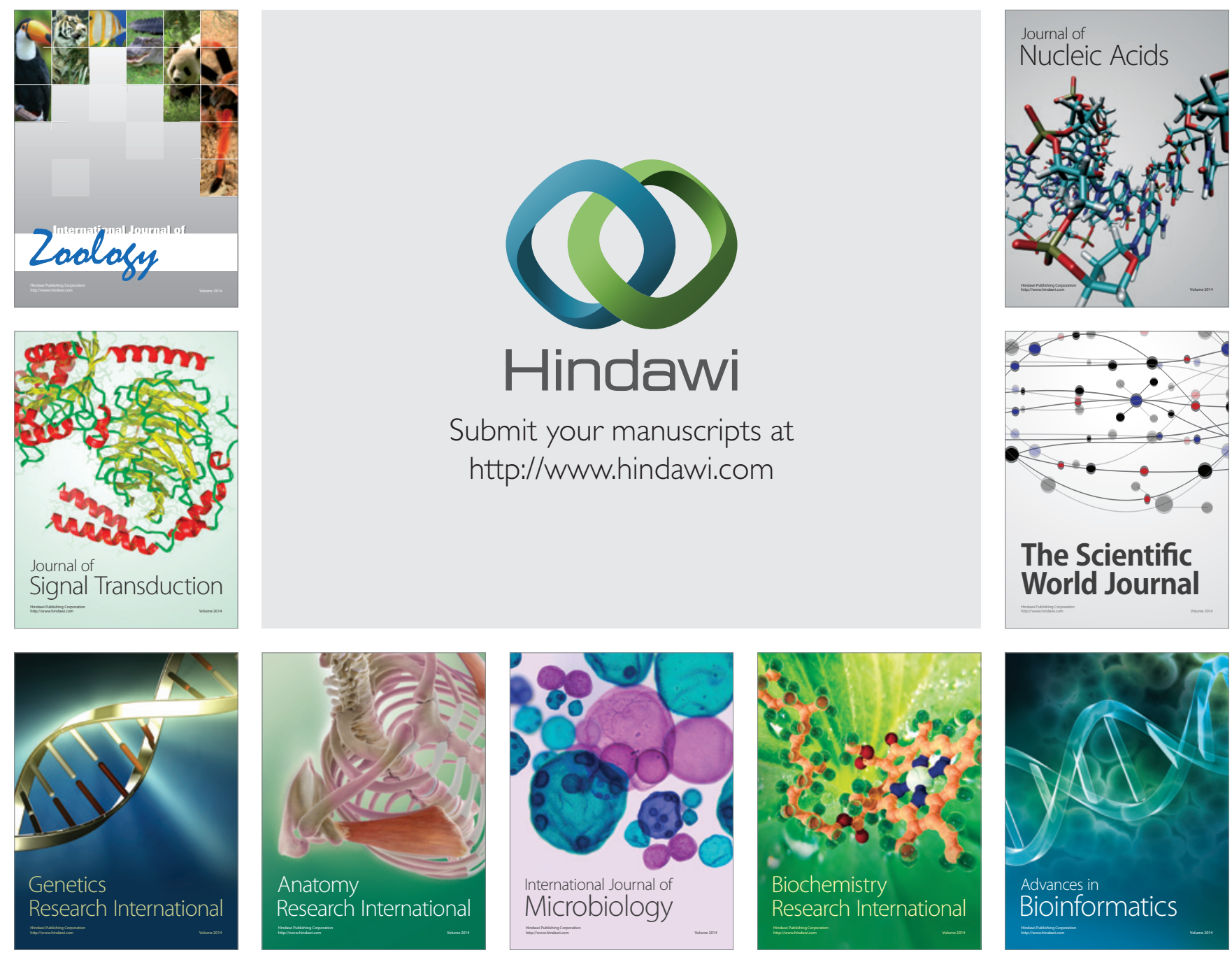

The Scientific World Journal
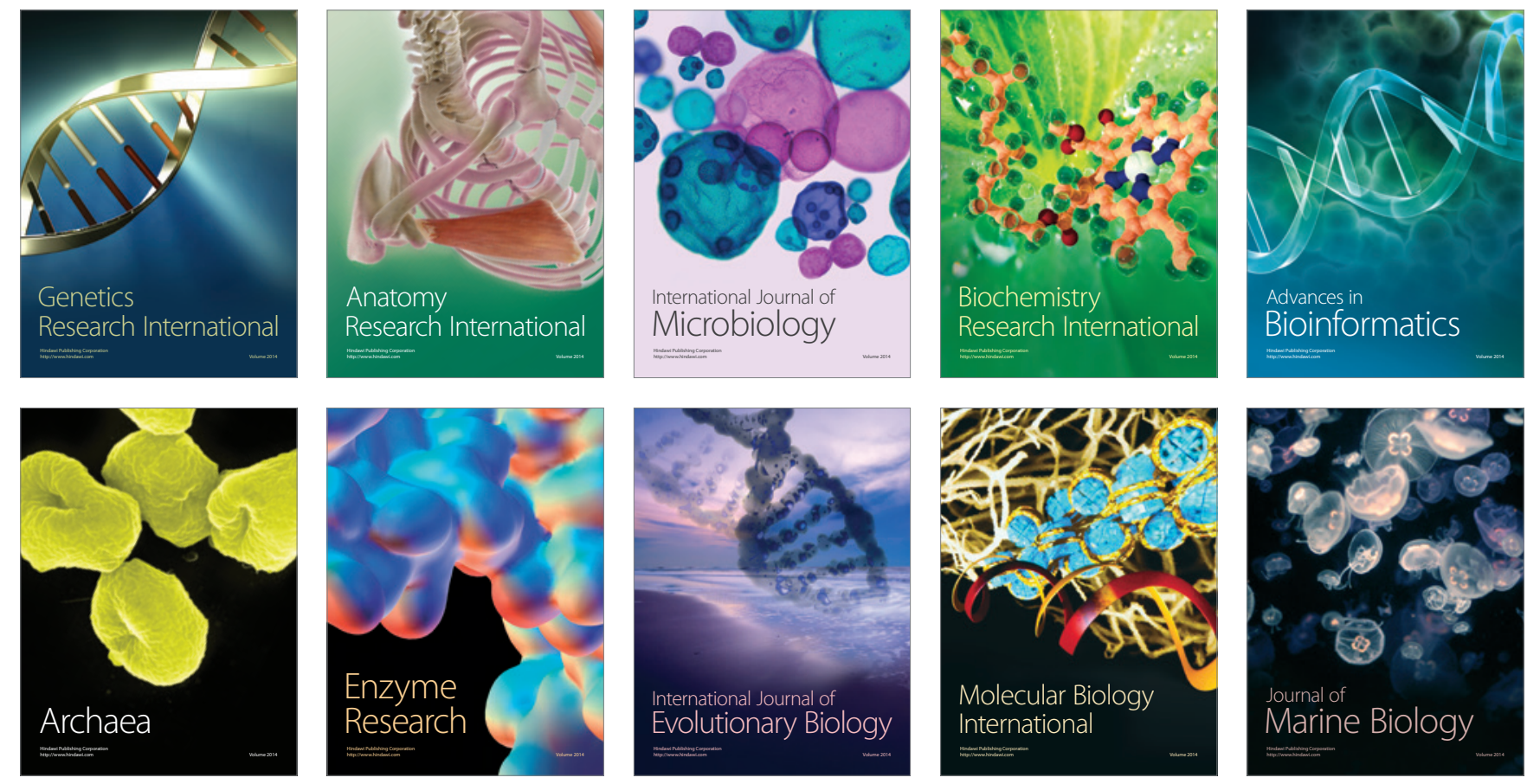